\title{
USING TEXT MODELS IN DIAGNOSTIC TASKS.
}

\section{WYKORZYSTANIE TEKSTOWYCH MODELI W ZADANIACH DIAGNOSTYKI}

\author{
Yuriy Korostil, Olga Korostil \\ Ukrainian Academy of Printing, Lviv \\ Maritime University of Szczecin, Poland, \\ e-mail: j.korostil@am.szczecin.pl; korostilo_15@meta.ua.
}

\begin{abstract}
This paper contains developing of a method of solving diagnostic tasks for complex technical objects (STO) based on using text models $\left(T M_{i}\right)$ to describe

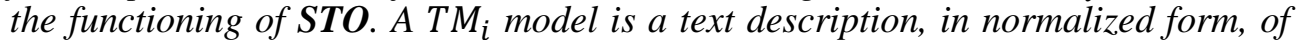
all fragments of $\boldsymbol{S T O}$ functioning process. The description of $T M_{i}$ is for med using semantic vocabularies of different types, which are generated on the basis of usage of information about all the aspects of STO construction and functioning. Such interpretation description is a subject area for tasks of STO diagnostics. Detection of malfunction and deviations of a functioning process of STO from an established functioning mode is implemented on the basis of analysis of semantic parameters of text description of the STO functioning process in order to determine semantic anomalies which occur in the descriptions of the STO functioning process, as well as in the descriptions of fragments of its functioning. Semantic anomalies occur in case when values of semantic parameters go beyond their established limits.
\end{abstract}

Keywords: complex technical objects, semantic parameters, text models.

Streszczenie: $W$ pracy przedstawione sa naukowe aspekty tworzenia systemów sterowania obiektami społecznymi. Opracowano strukture systemu sterujacego wraz $z$ uktadem monitorowania $i$ uktadem modelu tekstowego pomagajacego $w$ symulacji poszczególnych obiektów społecznych i środowiska społecznego jako całości. Do działań sterujacych używa się strumieni informacji, będacych tekstowymi opisami informacji, gdyz zakłada się, że maja one wplyw na poszczególne osoby tworzace obiekty spoteczne i na same obiekty spoleczne. W celu przeprowadzenia analizy istoty wptywu strumienia informacji $\left(I P_{i}\right)$ na obiekt spoteczny $\left(S O_{i}\right)$, a także dla analizy skuteczności jego wptywu na obiekt spoleczny, użyto modeli tekstowych $T M_{i}$, opisujacych odpowiednie obiekty spoleczne. Oprócz modeli tekstowych $i$ strumieni informacyjnych $w$ niniejszym artykule przedstawiono system monitorowania źródel informacji pochodzacych od poszczególnych osób, które stanowia $\mathrm{SO}_{i}$ oraz samego $\mathrm{SO}_{i}$. Opracowane w niniejszym artykule koncepcje modeli tekstowych $T M_{i}$ sa nowe nie tylko $w$ dziedzinie badań spolecznych, lecz również $w$ obszarze teorii regulacji automatycznej. Po raz pierwszy opracowano $i$ przebadano koncepcję zależności pomiędzy $T M_{i}$ a parametrami semantycznymi właściwymi dla $\mathrm{SO}_{i}$

Slowa kluczowe: obiekt społeczny, parametry semantyczne, modele tekstowe. 
Using text models in diagnostic tasks

Wykorzystanie tekstowych modeli $w$ zadaniach diagnostyki

\section{Introduction}

To solve tasks of diagnostics of complex technical objects (STO), we need to clarify the problem of classifying malfunctions, because different malfunction types require different methods of their detection. The following malfunction types can be assumed as the most general classification:

- designing malfunctions ( $p n)$;

- non-designing malfunctions $(\mathrm{nn})$.

Designing malfunctions are those which can be foreseen during the stage of STO designing. An example of such malfunctions can be those which occur due to foreseen changes of parameters characterizing STO and its certain units. Among these parameters can be a resource value of certain parts or units, inacceptable deviation values of the functional parameters if a representation of units or part allows to know what inacceptable changes in STO or its certain units could be caused by these deviations. In general this means that during STO designing it is possible to form dependencies between the causes of malfunctions and the parameters characterizing them.

The $n n$ type includes malfunctions which do not allow to determine dependencies between changes of functional parameters and possible changes of technical state of certain nodes or STO in general during the designing stage. Examples of such occurrences are as follows:

- a possibility for external negative factors to appear, with unknown parameters;

- absence of mathematical or empirical models connecting the processes of a different physical nature, which are used in $S T O$;

- when hidden designing mistakes occur, which did not become apparent during object testing and trial performance, etc.

The $p n$ malfunctions are diagnosed on the basis of data regarding diagnostic parameters and the possible causes of their discovery. Diagnostic parameters are used to recognize malfunctions, and the information about their causes of occurrence is used to localize the places of influence of negative factors which eventually lead to these malfunctions [1,2]. This is due to possible diversification of malfunction causes and malfunction effects in the STO structure.

In case of $n n$ malfunctions the following situations can occur:

- diagnostic parameters which describe the form of malfunction occurrence can be known while the causes of the occurrence are unknown,

- an occurring malfunction only appears as inacceptable changes of functioning modes of STO or its units, which means there is no data regarding both diagnostic parameters and causes of the corresponding malfunctions.

This paper describes a developed method of diagnostics of a $n n$ type malfunction, based on using text models $\mathrm{TM}_{\mathrm{i}}$. 


\section{Fundamentals of text model system}

A text model is a description of how to interpret a functioning process of an STO unit or $S T O$ as a whole in the normalized text form [3]. Building a $\mathrm{TM}_{\mathrm{i}}$ of a certain $S T O$ requires a description of a subject area containing STO, all of its components and external factors which could influence STO. This description consists of a set of semantic vocabularies $S c_{i}$ [4]. A semantic vocabulary consists of elements, which are text descriptions of words $x_{i}$ or phrases $\varphi_{i}$, and a text description of interpretation of the corresponding element:

$$
x_{i}:=<a_{i 1} * \ldots * a_{i n}>\mathrm{I}<p_{i 1}, \ldots, p_{i k}>,
$$

where $a_{i j}$ are words which make up the description of $x_{i}$ interpretation, and $p_{i j}$ are auxiliary parameters which can supplement the data regarding the $x_{i}$ element.

Describing the $T M_{i}$ requires using words or phrases $\left(x_{i} \vee \varphi_{i}\right) \in S c_{i}$. The $T M_{i}$ structure corresponds to the $S T O$ structure. For example, a sentence $\psi_{i}$, which consists of phrases $\varphi_{i}$, describes a certain fragment $\omega_{i}$ of a unit $W_{i}$, or $\omega_{i} \in W_{i}$. A paragraph $\pi_{i} \in T M_{i}$ describes a certain unit $W_{i}$ from $S T O$. A model $T M_{i}$ in general describes $S T O$. Formally you can write the following:

$$
\begin{aligned}
{\left[T M_{i}=\left(\pi_{1} * \ldots *\right)\right] \Rightarrow } & {\left[\pi_{i}=\left(\psi_{i 1} * \ldots * \psi_{i m}\right)\right] \Rightarrow\left[\psi_{i j}=\left(\varphi_{i j 1} * \ldots * \varphi_{i j k}\right)\right] \Rightarrow } \\
& \Rightarrow\left[\varphi_{i j k}=\left(x_{i j k 1} * \ldots * x_{i j k g}\right)\right] .
\end{aligned}
$$

For example, let us examine a description of one unit $W_{i}$ and assume a single phrase $\varphi_{i j k}$ is a separate component of the description. Then a formal description of this unit as a $T M_{i}$ can be written in the following way:

$$
T M_{i}=\pi_{i}=\left\{\psi_{i 1}\left(\varphi_{i 11} * \ldots * \varphi_{i 1 m}\right) * \ldots * \psi_{i n}\left(\varphi_{i n 1} * \ldots * \varphi_{i n k}\right)\right\} .
$$

A unit $W_{i}$ can be described with different accuracy of representing its structure and its functioning process. A $T M_{i}$ functioning description is an interpretative description of a current state of all the elements and represents their structure, its connection with a structural environment in the unit scope and parameters with their values, relevant to the described component and characterizing its state. A description of every parameter is extended by a description of a surrounding parameter which interacts with the parameter of the described element. In this description every element is supplemented with information describing a condition of synchronizing its functioning with others surrounding elements or parameters. Depending on the type of $W_{i}$, synchronization can be defined and, correspondingly, described at the level of the whole $W_{i}$.

During the functioning process of $W_{i}$ the following occurrences can take place:

- possible changes of parameters characterizing the current state of the functioning process; 
Using text models in diagnostic tasks

Wykorzystanie tekstowych modeli $w$ zadaniach diagnostyki

- besides the changes of the parameters, a $W_{i}$ structure configuration can change, which means during the functioning process certain unit elements are moving;

- an extension of such description can be a description of a process of transforming heat energy of fuel combustion into mechanical energy of bearings' movement in the engine cylinders, etc.

To simplify the task review let us confine ourselves with the first case. Within the scope of $T M_{i}$ values of the parameters displaying the functioning process are changing with specified ranges of accuracy, each of which displays a qualitative change in the corresponding processes. For example, for a cylinder pressure parameter the following value ranges, displayed in the text model, are specified:

- "acceptable" parameter values;

- "acceptable boundary" parameter values;

- "unacceptable" parameter values;

- "critical" parameter values, etc.

Values of these ranges for certain elements $\varphi_{i j k}$ in a vocabulary $S c_{i}$ are specified as parameters $p_{i j}$ which are part of the vocabulary. The functioning process of certain units and $S T O$ in general is continuous during a certain time interval $\Delta t_{i}$, and $T M_{i}$ is a certain text description. So let us examine how $T M_{i}$ displays the dynamics of the corresponding functioning process. In modern STO automated or automatic control systems are used. This means during the designing stage STO is equipped with a whole set of sensors for different parameters, including diagnostic parameters. Let us assume that, once it is operable, STO is functioning in the specified mode. Information about current values of the parameters $p_{i j}$ is transferred to the control system and the diagnostic system, built on the basis of using text models. Values of a parameter identified by the element $\varphi_{i j k}$ are transferred to the description of this element's parameters which are part of an interpretative description $\varphi_{i j k}$ in a vocabulary $S c_{i}$, which is the following vocabulary component:

$$
\varphi_{i j k}:=<a_{i j k 1} * \ldots * a_{i j k m}>\mathrm{I}<p_{i j k 1}, \ldots, p_{i j k q}>.
$$

If the current parameter value is within the range $p_{i j k c}$, where $1<c<q$, and the interpretative description of this range for $\varphi_{i j k}$ is used in the text description of $T M_{i}$ at the moment $t_{i}$, which corresponds to the moment when the corresponding parameter value is being read from a sensor, then there is no change of $\varphi_{i j k}$ parameter value in $T M_{i}$. Otherwise, if the current value of the $p_{i j}$ parameter falls within the range $p_{i j k r}$, where $(1<r<q) \&(r \neq c)$, then the text interpretation "...cylinder pressure parameter is within (acceptable limits)..." is changed with the following interpretation: "...cylinder pressure parameter is within (unacceptable limits)..." if the $p_{i j k r}$ range corresponds to such interpretation. 
There are also parameters which represent structural changes. A possible example of these is a parameter of range of a slider movement along the guide, which can be described as follows:

- "the slider does not reach the border limiters",

- "the slider has reached the border limiters",

- "the slider has not changed direction after reaching the border limiters" and so on.

In these cases the corresponding changes are made within $T M_{i}$, in the descriptions of text interpretation of the corresponding $\varphi_{i j k}$ components. Thus, $T M_{i}$ represents the dynamics of changes in $W_{i}$, which displays the functioning process of the corresponding unit.

\section{Method of solving a diagnostic task}

To solve a diagnostic task on the basis of using $T M_{i}$, which includes the description of STO structure and the description of the functioning process $\left(\operatorname{Pr}_{i}(S T O)\right)$, we require tools for analyzing the corresponding text descriptions. Such analysis tools are semantic parametersu $\sigma_{i}$ which allow to conduct not only qualitative analysis but also quantitative analysis of the corresponding parameters. In the scope of this paper the following semantic parameters will be used $[5,6]$ :

- semantic contradiction $\left(\sigma^{S}\right)$,

- semantic conflict $\left(\sigma^{K}\right)$,

- semantic redundancy $\left(\sigma^{N}\right)$,

- semantic insufficiency $\left(\sigma^{D}\right)$.

Interpretation of these parameters is natural for text descriptions and represents particularities of perception of certain text features by the reader. For example, semantic contradiction defines a situation when a sentence contains words or phrases which contradict each other to a degree. Semantic conflict defines a situation when a sentence contains two consequent phrases which describe two different entities both equally subject by the previous text fragment of the corresponding sentence. As distinct from semantic conflict, semantic redundancy occurs in case of two corresponding phrases represent two equal entities in different forms. Semantic insufficiency defines a situation opposite to the one with semantic redundancy.

In order to get quantitative results of the semantic analysis, we need to have methods of numeric valuation of the stated parameters. According to $[7,8]$, calculation of values of semantic parameters is based on using a basic semantic parameter, which is semantic meaningfulness of a text $\sigma^{Z}$ consisting of one word or one phrase. Definition of semantic meaningfulness is performed by different ways, among which are:

- involvement of the experts in the subject area,

- calculating the number of words in the descriptions of interpretative extensions of certain elements in semantic vocabularies, provided these descriptions are normalized,

- number of occurrences of a certain word or a phrase within one model $T M_{i}$. 
Using text models in diagnostic tasks

Wykorzystanie tekstowych modeli $w$ zadaniach diagnostyki

Another way is based on an assumption that, the more important the elements are for the functioning of STO, the more complete their interpretative description should be and the more words are needed to describe them.

When using semantic parameters in analysis of text descriptions, intervals of acceptable and unacceptable values are defined to determine their values, and these intervals are marked $\delta \sigma^{*}$. For example, the value of semantic contradiction is defined as an absolute difference value of semantic meaningfulness of two words the semantic contradiction is measured between:

$$
\sigma^{S}\left(\varphi_{i}, \varphi_{j}\right)=\left|\sigma^{Z}\left(\varphi_{i}\right)-\sigma^{Z}\left(\varphi_{j}\right)\right| .
$$

The basic diagnostic task is to detect malfunctions occurring in a technical object and to determine the causes of this malfunction $[9,10]$. Detection of a malfunction when using $T M_{i}$ is based on detecting semantic anomalies.

Definition 1. A semantic anomaly $\left(\alpha \sigma_{i}\right)$ is a fragment in a text description $T M_{i}$ where at least one semantic parameter is outside of a set range.

In this case detecting malfunctions consists of calculating the values of semantic parameters $\sigma^{S}, \sigma^{K}, \sigma^{N}, \sigma^{D}$. Let us assume that in the initial version there are no semantic anomalies in the $T M_{i}$. So, semantic analysis can be performed only in case when changes have occurred in the $T M_{i}$. This analysis can be performed firstly within the boundaries of the fragments where the changes took place. The boundaries of such fragment of a text description, during the initial stage of analysis, can be defined by size of the sentence where the changes occurred. Certain boundary values of semantic parameters are defined for each STO and each $\operatorname{Pr}_{i}($ STO $)$ on the basis of expert analysis performed by specialists during the STO designing stage. The $\delta \sigma_{i}$ values can change during the STO functioning. The text description of the fragment where changes occurred, in the scope of a system of text model tools, allows to generate output of text descriptions which interpret the detected malfunction in the subject area of the corresponding STO.

To determine the causes of malfunction, given that it is localized in another fragment of the STO structure regarding the fragment where the malfunction occurred, within the $T M_{i}$ a description is implemented of a sequence of events in STO which have caused a semantic anomaly. Let us review the following proposition.

Proposition 1. A text description of a model $T M_{i}$ of an object $S T O$ describes, as a given approximation, all aspects defining $\operatorname{Pr}_{i}(S T O)$, which is formally described by the following relation:

$$
\forall\left(x_{i} \in T M_{i}\right) T \exists x_{i}\left\{\left[\operatorname{Pr}_{i}\left(T M_{i}\right) \rightarrow\left(x_{i} \notin S T O\right)\right]\right\} .
$$

Let us review the following statement. 
Statement 1. If a semantic anomaly occurred in $T M_{i}$, then there are descriptions within the limits of $T M_{i}$ which have caused the corresponding anomaly.

Let us assume that in $t m_{i} \rightarrow \alpha \sigma_{i}$. This means $\sigma_{i}\left(\varphi_{i}, \varphi_{j}\right)>\delta \sigma_{i}$ exists in $t m_{i}$. It results from this that values $\left[\sigma^{Z}\left(\varphi_{i}\right) \vee \sigma^{Z}\left(\varphi_{j}\right)\right]$ have changed in $\left(\varphi_{j} \vee \varphi_{i}\right)$. If $\Delta \sigma^{Z}\left(\varphi_{j}\right)>\tau_{j}$, where $\tau_{j}$ is a boundary for regulating a parameter $\varphi_{j}=\xi_{j}$, where $\xi_{j}$ is a parameter of a process $\operatorname{Pr}_{i}(S T O)$, which corresponds to $\varphi_{i}$ in $T M_{i}$, this means there is a function $y_{j}=f\left(y_{k}\right)$ in STO and, respectively, there is an element $\varphi_{k}$ В in $T M_{i}$ which is connected to $\varphi_{j}$ by a text fragment $j\left(f\left(\varphi_{k}, \varphi_{j}\right)\right)$. If the $T M_{i}$ has $\sigma_{i}^{S}\left(\varphi_{k}, \varphi_{j}\right) \leq \delta \sigma^{S}$, then $\left[\sigma_{i}^{S}\left(\varphi_{i}, \varphi_{j}\right) \in t m_{i}\right] \&\left(\alpha \sigma_{i} \in t m_{i}\right)$, which means a malfunction occurs in $\left(\varphi_{i}, \varphi_{j}\right)$, which can be interpreted as a malfunction in $\omega_{i} \in S T O$. Let us assume $\sigma_{i}^{S}\left(\varphi_{k}, \varphi_{i}\right) \leq \delta \sigma^{S}$, then in STO exists $\xi_{i}=f\left(\xi_{k}\right)$, such that $j\left(f\left(\varphi_{k}, \varphi_{i}\right)\right) \rightarrow \sigma_{i}^{S}\left(\varphi_{k}, \varphi_{i}\right) \geq \delta \sigma_{i}$. This means there is such $\operatorname{tm}_{j}$ in $T M_{i}$, where $j\left(f\left(\varphi_{k}, \varphi_{r}\right)\right)$ is described. If $\sigma_{i}^{S}\left(\varphi_{k}, \varphi_{r}\right) \geq \delta \sigma^{S}$, the malfunction is in $\varphi_{r}$. If $\sigma_{i}^{S}\left(\varphi_{k}, \varphi_{r}\right) \leq \delta \sigma^{S}$, then we proceed to $\varphi_{h}$ for which $j\left(f\left(\varphi_{r}, \varphi_{h}\right)\right)$ exists in $T M_{i}$. Because $S T O$ is structurally finite, $T M_{i}$ is a finite description. Besides, $T M_{i}$ is complete with a given approximation $\varepsilon$. This means that when continuing the chain of semantic analysis within $T M_{i}$ looking like $\varphi_{i} \rightarrow \varphi_{j} \rightarrow \varphi_{r} \rightarrow \cdots \rightarrow \varphi_{h}$, we will achieve $\varphi_{g}^{*}$, for which $\sigma_{i}^{S}\left(\varphi_{g-1}, \varphi_{g}\right) \geq \delta \sigma^{S}$. Then $\varphi_{g}^{*}$ identifies the place which causes the malfunction in $\varphi_{i}$.

In order to use $T M_{i}$ for diagnostics, it is necessary to generate not only $S c_{i}$ but also a system of boundary values for semantic parameters used in the semantic analysis. Each type of semantic parameters requires to generate a vocabulary of their interpretations, which represents the relations of boundary values $\delta \sigma_{i}$ with unacceptable deviations in $\operatorname{Pr}_{i}(S T O)$. For example, if $\xi_{i}=f\left(\xi_{j}\right)$ takes place, which is represented in $\operatorname{tm}_{i} \in T M_{i}$ as $\left(\varphi_{i} * \varphi_{j}\right)$ and, respectively, $\sigma^{S}\left(\varphi_{i}, \varphi_{j}\right)>$ $\delta \sigma^{S}$ exists, this means that $T\left(\varphi_{i} \rightarrow \varphi_{j}\right)$ is taking place. This is interpreted as an unacceptable difference value between $\xi_{i}$ and $\xi_{j}$. When the case in question is $\sigma^{K}\left(\varphi_{i}, \varphi_{j}\right)$, this parameter represents an unacceptable value of similarity between $\left(\varphi_{i}\right)$ and $\left(\varphi_{j}\right)$. From the point of view of functional interpretation of $\sigma^{K}$ this means $T\left\{\left[\xi_{i}=f\left(\xi_{m}\right)\right] \leftrightarrow\left[\xi_{j}=f\left(\xi_{r}\right)\right]\right\}$. Interpretations for $\sigma^{N}$ and $\sigma^{D}$ can be formed in a similar way.

\section{Summary}

When using conceptions of a text model system, it is possible to solve basic diagnostic tasks, such as detecting malfunctions and determining their causes. When doing so, the corresponding $T M_{i}$ must be complete in the given scope of STO description. Thanks to representation of all parameters in $T M_{i}$, provided for by given ranges of parameters, and critical changes occurring in $\operatorname{Pr}_{i}(S T O)$, it is possible to detect non-designing malfunctions. This is possible because, when solving diagnostic tasks, it is not necessary to use explicit, or empirical dependencies between parameters, which, when changed, can lead to unacceptable deviations and, respectively, to occurrence of malfunctions.

Thanks to using text descriptions of the functioning process of STO, it is possible to detect situations that can be interpreted as manifestations of malfunctions, on 
Using text models in diagnostic tasks

Wykorzystanie tekstowych modeli $w$ zadaniach diagnostyki

a level of text interpretations of the functioning process, corresponding to changes in the process.

In the scope of the proposed approach it is possible to supply operators or the maintenance staff with information regarding negative changes in the STO functioning process in a user-friendly form to directly perceive the corresponding events in a technical system.

\section{References}

[1] Cholewa W., Kisiński J. Diagnostyka techniczna. Odwrotne modele diagnostyczne. - Gliwice: Wyd. Politechniki Śląskiej, 1997. -178 s.

[2] Chiang L.H., Russel E.L., Brata R.D. Fault Detection and Diagnosis in Industrial System. - : London: Springer Verlag, 2001. -237 p.

[3] Korostil Y., Korostil O. Aanalysis and interpretation of text models. / Journal of KONBIN N4(24), Warszawa, 2012. 93-104 p.

[4] Korostil O., Korostil Y. Using text models in navigation../ Scientific Journals Maritime University of Szczecin, 38(110), 2014. pp. 45-49.

[5] Korostil Y., Korostil O. Methods of extension of abilities of text models' semantic analysis./ Scientific Journals Maritime University of Szczecin, 35(107), 2013.pp. 90-96.

[6] Vardul F. Basics of descriptive linguistics. Syntax and suprasyntax. Moscow: KomKniga, 2006. - $352 \mathrm{p}$.

[7] Volf E.M. Functional semantics. Moscow: KomKniga, 2002. - 262 p.

[8] Durnyak B.V., Korostil O.Y. Designing of advertisement in the Internet network on the basis of its semantic analysis. Lviv: Ukrainian Academy of Printing, 2014. - $136 \mathrm{p}$.

[9] Trukhachov A.A. Analysis of procedures and algorithms of signal detection. Moscow: Radio i Svyaz, 2004. - 247 p.

[10] Technical diagnostics. Reference book. Moscow: Mashinostroyeniye, 1989. 423p.

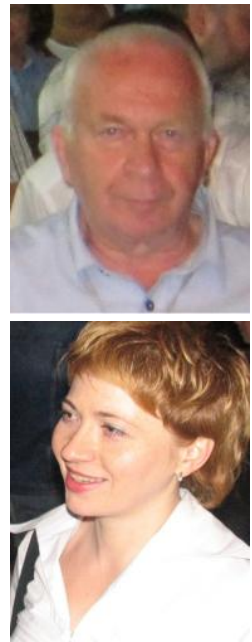

YuriyKorostil, Professor, Doctor of Science, Maritime University of Szczecin, Poland,

Olga Korostil Candidate of Science, Ukrainian Academy of Printing, Lviv 